\title{
Reducing parental anxiety using a family based intervention for youth mental health: A randomized controlled trial
}

\author{
Melanie D. Bertino, Karen Richens, Tess Knight, John W. Toumbourou, Lina Ricciardelli, \\ Andrew J. Lewis
}

Centre for Mental Health and Wellbeing Research, School of Psychology, Deakin University, Burwood, Australia

Email: melanie.bertino@deakin.edu.au

Received 29 December 2012; revised 30 January 2013; accepted 9 February 2013

\section{ABSTRACT}

This paper presents findings on parent anxiety and attachment relationship style from the Deakin Family Options (DFO) pilot study, a randomized controlled pilot study comparing a family-based treatment (BEST Plus), versus a youth only treatment (CBT) versus a group who received both of these treatments (COMBINED). Eligible participants were families with a young person (aged 12 - 25 years) with a high prevalence mental health problem. Youth from participating families scored in the clinical or subclinical range for depression, anxiety and/or substance misuse symptoms on standardized measures during the initial assessment. The collected sample was drawn from regional and urban centers in Victoria, Australia and allocated to treatment condition using a simple randomization procedure (parallel design). It was hypothesized that families receiving the BEST Plus would experience greater reductions in youth and parent mental health symptoms, and improved parent-child relationships, compared with those in the CBT condition. This paper describes and discusses changes in parent anxiety and parent attachment, according to whether the parent participated in a treatment (BEST Plus) or did not (NONBEST Plus). Participants were blind to the study hypotheses. In total 71 parent participants returned pre data and were allocated to a treatment group. In this paper, data from parent participants who completed pre and post measures $(n=48)$ and pre, post, and 6-month follow-up measures $(n=28)$ on anxiety and attachment were analyzed by group (BEST Plus versus NONBEST Plus). The results of this study suggest that parent anxiety decreased significantly more following parent involvement in a group treatment, than for parents that did not receive treatment. Unexpectedly, avoidant attachment increased in the no treatment group, but remained relatively stable following the BEST Plus group. There were no significant findings in relation to compulsive traits and anxious attachment. These findings are discussed in light of the study limitations.

Keywords: Adolescent; Parenting; Anxiety; Depression; Attachment; Randomized Controlled Trial

\section{INTRODUCTION}

Anxiety has been defined in many ways, but has long been understood to be a negative experience of physical, cognitive, behavioural and/or emotional responses [1]. Although a normal reaction to a stressful event, anxiety becomes problematic (and a component of a mental health disorder) when it interferes considerably with daily living: impairing functioning in one or more areas of life such as relationships, occupational or academic performance, and social activities [2]. Anxiety disorders are the most common mental disorders in Australia, with 12 month prevalence rates estimated at $14.4 \%$ and lifetime rates estimated at $25 \%$ of the population [3]. Having an anxiety disorder also places sufferers at risk of developing co-morbid disorders such as depression or substance abuse, and increases the risk of suicide [2].

Proposed aetiological processes in the development of anxiety disorders include a range of biological, psychological and social factors [2]. These include but are not limited to: the role of neural changes, heredity components and intergenerational transmission of anxiety disorders, a "shy" temperament, low self-esteem, cognitive biases (e.g. perfectionism, high need for control), poor coping skills, avoidant behavioural tendencies, and stressful past life experiences and events [4-7]. Parental anxiety is also strongly associated with the development and maintenance of anxiety and depression in offspring $[5,8]$. Exposing children to anxiety-provoking experiences, modeling of anxious affect and avoidance, and/or intru- 
sive parenting styles may place children at a higher risk of developing an anxiety disorder $[9,10]$.

Additionally, parents and caregivers of youth with physical and mental health disorders themselves commonly experience significant and increased rates of distress and burden [11]. A group who may be particularly at risk for poor mental health include the parents of adolescents or young adults with one or more common mental health problems, such as anxiety, depression and substance abuse [12]. Parents of youth with these concerns have commonly reported feelings of guilt and worry about whether they may be somehow at fault for their child's condition, uncertainty about how best to support their child, or confusion about locating and eliciting appropriate professional help [13].

To date there has been a limited focus in the research literature on the role of parental anxiety on treatment outcomes for youth with high prevalence mental health problems (e.g. anxiety, depression and substance misuse). The most commonly evaluated form of treatment for these problems is individual cognitive behavioral therapy (CBT) or Interpersonal Therapy (IPT) for the adolescent/young adult [14-17], motivational interviewing (MI) for the youth with substance use problems [18-20] or group therapies for the youth [21-23]. Family therapy has tended to be evaluated in younger children and early or pre-adolescents [24-26], however, there are several notable exceptions [27-30]. The presence or absence of parent anxiety does not solely predict youth treatment outcomes [26,31-36]. Additional family factors have been identified that, when combined with parent anxiety, enhance our ability to predict treatment outcomes in youth. For example, paternal rejection and depression, maternal emotional warmth [33] parental attendance and engagement [37], family cohesion [35], family dysfunction, parental frustration, maternal parenting stress [36], overintrusive parenting style [32], and maternal depressive symptoms [38] have been found to predict parent and youth mental health outcomes in psychological therapies.

In terms of common youth mental health disorders, individual treatments such as CBT have reasonable supporting evidence, and family therapy has emerging evidence, for these high prevalence youth mental health problems $[20,26,28,31,32,39,40]$. However, with regards to effectiveness and generalizability beyond the controlled research setting, a number of studies have found that a considerable proportion of youth with mental health disorders do not seek professional help or else refuse help that is offered $[12,41,42]$. Less than one quarter of youth who have diagnosable mental health issues receive services $[43,44]$. Some of the reasons parents have given for not commencing the help seeking process include being unsure of what to expect, being unclear how to access services, cost, thinking they can manage without help, and youth refusing to attend [41, 45]. Parents report being unsure how to help when their young people experience mental health problems yet are unwilling to attend treatment. In such families there is a risk of youth and parents becoming increasingly polarized and disconnected.

Parents experiencing anxiety may benefit from seeking their own individual treatment, reasons for which are twofold; to prohibit the opportunity for parents to exhibit any maladaptive behaviours potentially impacting adversely on their child's treatment, and to address any maladaptive behaviours perpetuating their child's mental health problem and explore ways to assist their child with mental health improvements. Programs that are designed to provide support and education for parents typically focus on aspects such as supporting carers to practice self-care and contain distress symptoms. There is some evidence for such programs improving carer mental health (stress, maternal/paternal anxiety and depressive symptoms), which may in turn have an effect on youth mental health $[29,30,46]$.

One such program that has been developed over the past decade is the Behaviour Exchange Systems Training (BEST) program. This program was originally designed to provide education and support to parents affected by youth drug abuse, a need that was often overlooked in the treatment of youth substance abuse [29]. The aim of the program was to provide support and assistance to parents and to influence youth substance abuse by improving parental mental health and parenting competence. The program targeted parent emotional well-being, responsibility and shame, and assertive parenting responses. It was delivered in a group format with an educational focus. Early evaluation of BEST found reductions in parental mental health symptoms, improved parental satisfaction and the increased use of assertive parenting techniques [29]. The BEST program was further developed over time with ongoing evaluation to meet the concerns expressed by families. It evolved into the BEST Plus program in 2003 as a whole-of-family therapy program based on a family systems approach [30]. Evaluations of the BEST Plus program found improved parental emotional dependence on adolescent behaviour to be associated with a reduction in negative stress symptoms, and that this reduction in parental stress, combined with siblings attending the program, contributed to improvements in cohesive family behaviour [46]. In the present Deakin Family Options pilot study, the BEST Plus program was evaluated with families where the youth (12 25) were experiencing substance misuse, depression and/or anxiety symptoms, and the youth of concern was also invited to attend the final four sessions of the program along with their siblings and parents $[13,47]$.

The Deakin Family Options (DFO) pilot study com- 
menced in 2008 and was designed to compare the relative efficacy of family-based treatment (BEST Plus), to an individual youth treatment (CBT) for high prevalence youth mental health problems. The broad aim of the DFO study was to determine whether families receiving the BEST Plus intervention would experience greater reductions in youth and parent mental health symptoms, and improved parent-child relationships, compared with those in the CBT condition. This paper describes and discusses pre, post and 6 month follow-up data relating to changes in parent anxiety, and pre and post data on parent attachment relationship style, according to the type of treatment received. It was hypothesized that parent participants involved in the treatment (BEST Plus) would experience greater reductions in anxiety and reduced anxious and avoidant attachment, compared with parents who did not receive BEST Plus.

\section{METHOD}

\subsection{Design}

The DFO study was designed as a Randomized Controlled Trial employing a parallel groups design, with random allocation to one of three groups. The groups included BEST Plus, an individual CBT with the young person, or a combined condition where the family received BEST Plus and the youth concurrently received CBT. Participants were allocated using a simple randomization procedure following assessment, based on a computer generated random number sequence. This paper reports the data on parent anxiety and attachment in two groups: those parents who completed a treatment (via allocation to BEST Plus or COMBINED) and those who did not complete a treatment (CBT or no treatment). Only those parents who returned completed pre-measures at assessment (T1) and post-measures (T2) were included in analyses. Six-month follow-up data (T3) for these outcome measures were also analyzed. Participants were blind to the study hypotheses throughout their participation. Outcome data were collected via self-report measures posted back to the research manager, who was not involved in conducting the interventions.

\subsection{Participants}

The Participants were recruited from both clinical and community settings, including a family relationship counseling service, a major hospital, university, school counselor referrals, a community parenting seminar hosted by this research team at multiple sites, and direct selfreferrals (word of mouth). The parenting seminars were advertised in local newspapers and attending parents were provided with general information about youth mental health signs and symptoms, project information, and were invited to express their interest in being con- tacted about further participation. The services were delivered at a regional site in Geelong (Deakin University) and in urban Melbourne (drummond street services and Deakin University), located in Victoria, Australia. Informed consent was gained from all participating individuals (parent and youth), and parental consent was also obtained for all participating youth under the age of 18 . The trial was also approved by the Deakin University and Barwon Health Ethics Committees, and was registered with the Australia and New Zealand Clinical Trials Registry (ACTRN\#12609000630213).

To be included in the study, participants were required to: 1) have a "youth" in the family aged 12 - 25 years of age, who scored in the clinical or subclinical range for symptoms of anxiety, depression and/or substance misuse; 2) be willing to enter the evaluation; and 3) be able to participate in the groups. Participants were excluded from the study if: 1) the youth of concern had an intellectual disability or autism; 2) parents did not wish to participate; 3) youth or parents presented with severe mental illness requiring inpatient treatment; or 4) there was insufficient address for follow-up, or unwillingness to return for follow-up. Clinical range for depression, anxiety and/or substance misuse symptoms was assessed using standardized measures during the initial assessment (Youth Self-Report (YSR) [48] for young people aged 12 - 17 years, the Adult Self-Report (ASR) [49] for young people aged 18 - 25 years, and the Substance Abuse Subtle Screening Inventory (SASSI-A2) [50].

A total of $n=86$ families comprising $n=186$ participants completed at minimum a short intake interview for the DFO pilot study, conducted from 2008 to 2011. These participants included 71 youth $(38.2 \%), 70$ mothers $(37.6 \%), 29$ fathers (15.6\%), 13 siblings (7\%) and 3 stepparents $(1.6 \%)$. Following a clinical assessment determining suitability for the study, the number of eligible parent participants who returned pre-data reduced to 71 parents (see Figure 1). Reasons for this included "not meeting inclusion criteria" or "other" reasons (e.g. logistics, travel, time). In total 54 parent participants were randomized to the BEST Plus or COMBINED conditions, and 17 were randomized to CBT. A further 15 parent participants withdrew prior to randomization, however completed pre-post measures as a (non-randomized) no treatment comparison group for the study. Completed pre-post data were returned by 48 parents, and 6 month follow-up measures were returned by 28 parents, mostly in the BEST Plus condition (see Figure 1).

Of the 71 participating parents (including step-parents) that completed pre data, there were 48 mothers and 23 fathers. There were 35 male youth and 36 female youth represented in this sample. Parents were aged between 33 and 64 years $(\mathrm{M}=48, \mathrm{SD}=6.8)$. Youth were aged between 12 and 24 years $(\mathrm{M}=16.4, \mathrm{SD}=2.9)$. Table 1 


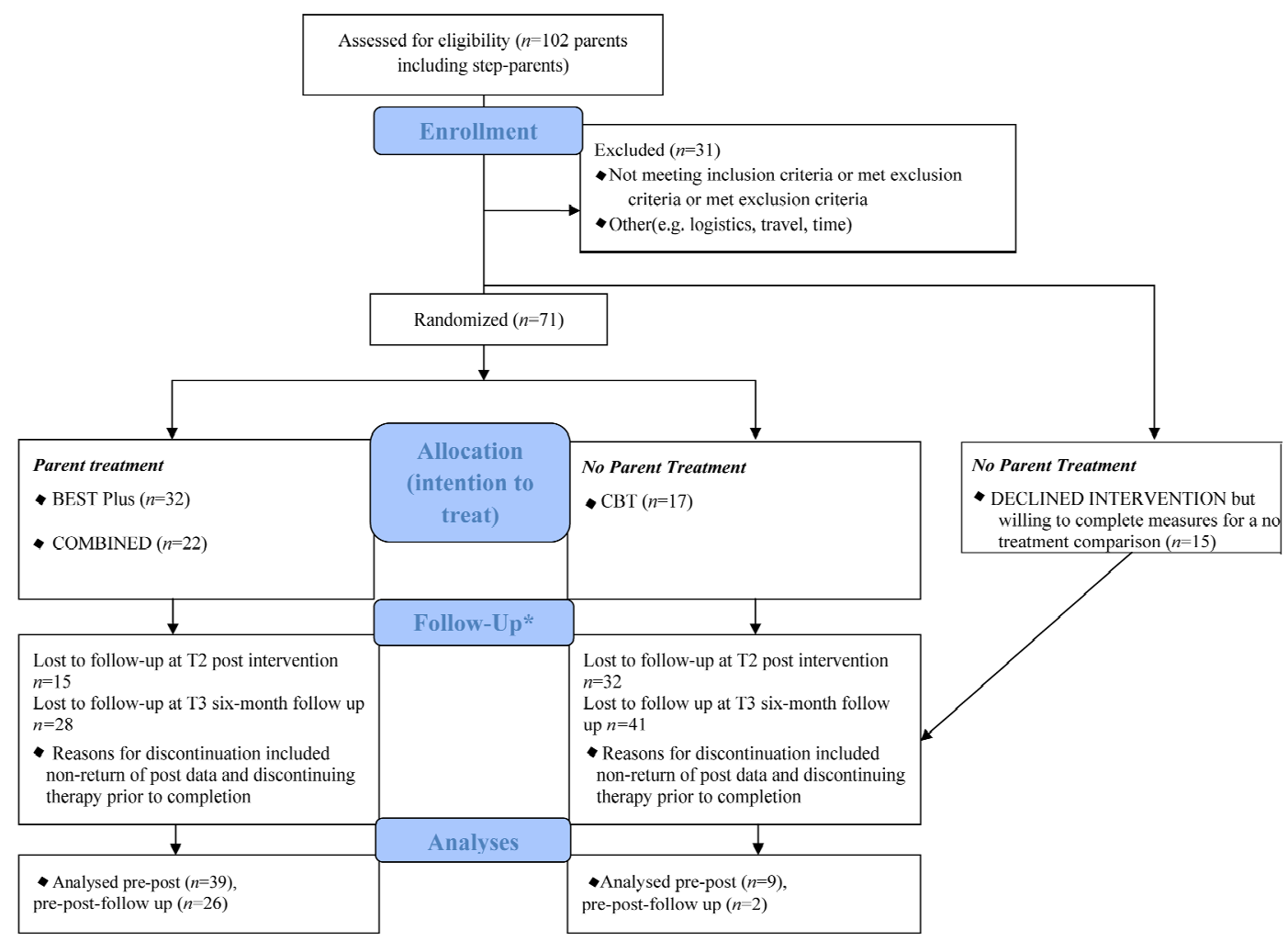

Figure 1. Flow diagram for parent participants in the DFO study. ${ }^{*}$ Describes the numbers of parents providing follow up data in BEST Plus and No Parent Treatment conditions. There was also a COMBINED condition to which $n=22$ parents were allocated, but only $n=2$ parents completed the interventions and returned all completed data in this condition. These numbers were therefore added to the BEST Plus group for this table - as this paper is comparing parents who received treatment versus parents who did not.

Table 1. Participant age and gender demographics by treatment condition $(N=71)$.

\begin{tabular}{|c|c|c|c|c|c|}
\hline & Measures Completed & Total $(n)$ & BEST Plus $(n)$ & NONBEST Plus $(n)$ & Between Groups Difference \\
\hline \multirow[t]{3}{*}{ Parent Gender: Male } & Pre Only & 7 & $6(86 \%)$ & $1(14 \%)$ & \\
\hline & Pre-post & 16 & $13(81 \%)$ & $3(19 \%)$ & $\chi^{2}=0.07, p=0.79$ \\
\hline & Total & 23 & 19 & 4 & \\
\hline \multirow[t]{3}{*}{ Parent Gender: Female } & Pre Only & 16 & $11(69 \%)$ & $5(31 \%)$ & \\
\hline & Pre-post & 32 & $26(81 \%)$ & $6(19 \%)$ & $\chi^{2}=0.7, p=0.79$ \\
\hline & Total & 48 & 37 & 11 & \\
\hline \multirow[t]{3}{*}{ Youth Gender: Male } & Pre Only & 11 & $11(100 \%)$ & $0(0 \%)$ & \\
\hline & Pre-post & 24 & $21(87.5 \%)$ & $3(12.5 \%)$ & $\chi^{2}=1.5, p=0.22$ \\
\hline & Total & 35 & 32 & 3 & \\
\hline \multirow[t]{4}{*}{ Youth Gender: Female } & Pre Only & 12 & $6(50 \%)$ & $6(50 \%)$ & \\
\hline & Pre-post & 24 & $6(25 \%)$ & $18(75 \%)$ & $\chi^{2}=2.3, p=0.13$ \\
\hline & Total & 36 & 12 & 24 & \\
\hline & Measures Completed & Total M (SD) & BEST Plus M (SD) & NONBEST Plus M (SD) & Between Groups Difference \\
\hline \multirow[t]{3}{*}{ Parent Age } & Pre Only & $46.8(7.8)$ & $48(7.4)$ & $43.8(9.2)$ & $t(15)=0.8, \mathrm{p}=0.39$ \\
\hline & Pre-post & $49.2(5.7)$ & $49.2(5.7)$ & $\mathrm{n} / \mathrm{a}$ & $\mathrm{n} / \mathrm{a}$ \\
\hline & Missing $(n=29)$ & & & & \\
\hline \multirow[t]{3}{*}{ Youth Age } & Pre Only $(n=22)$ & $15.9(2.3)$ & $16(2.8)$ & $15.5(3.7)$ & $t(20)=0.3, \mathrm{p}=0.77$ \\
\hline & Pre-post $(n=48)$ & $16.9(3.4)$ & $16.6(3.2)$ & $18.1(4)$ & $t(46)=1.2, p=0.24$ \\
\hline & Missing $(n=1)$ & & & & \\
\hline
\end{tabular}


presents detailed age and gender information for youth and parents; comparing participants across treatment groups who: 1) entered the study (T1); and 2) completed pre-post measures (T2).

\subsection{Materials}

Parent anxiety was assessed using the Millon Clinical Multiaxial Inventory (third edition) (MCMI-III) [51]. Three subscales of the MCMI-III assessed the anxiety outcomes reported in this paper: the anxiety, avoidant, and compulsive subscales. The MCMI-III is a 175 item questionnaire scored as true or false which assesses mental health, with scales for personality (Axis II) and clinical (Axis I) syndromes. The MCMI is widely used in clinical research, and was designed to assess correlates of mental health disorders as defined by the Diagnostic and Statistical Manual of Mental Disorders, third edition (DSM-III) [52]. The MCMI-III demonstrates strong internal consistency across the subscales (with alpha coefficients ranging from 0.66 to 0.90 ) and moderate to high test-retest reliabilities (median of 0.78 on the personality scales and 0.80 on the clinical scales for repetition within 6 months or less, and range from 0.59 to 0.73 for repetition after 4 years) [53]. Construct validity of the MCMI-I II anxiety and avoidance subscales with other measures of these constructs is reasonable to good [54], albeit with some convergence between depression and anxiety constructs assessed with the MCMI-III anxiety subscale in one study of 696 depressed and anxious outpatients [55]. Parent attachment relationship style was assessed using the Relationship Scales Questionnaire (RSQ) [56]. The RSQ is a 30 item measure which contains items from Hazan and Shaver's (1987) attachment measure [57], Bartholomew and Horowitz's (1991) Relationship Questionnaire [58], and Collins and Read's (1990) Adult Attachment Scale (AAS) [59]. Respondents rate themselves on a 5-point scale, the degree to which each statement "best describes their characteristic style in close relationships". The measure can be scored in different ways, but the preferred and more reliable method is to obtain continuous rather than categorical scores for the attachment styles [60]. In the present study, the RSQ was used to elicit continuous ratings for parents on two of the Hazen and Shaver attachment styles (anxious, avoidant) at assessment, and repeated at post intervention. Avoidant attachment describes persons who experience discomfort being close, trusting or depending on other people. Anxiously attached individuals report a desire for increasing levels of intimacy in interpersonal relationships; however such intimacy concurrently also arouses fears in the individual [61]. Internal consistency of the RSQ subscales is reasonable $(0.41$ and 0.70 for the attachment patterns) [56]. It has also demonstrated good 8 month test-retest reliability and construct, convergent and discriminate validity for the two underlying dimensions [44]. There were additional measures administered to parents, siblings and youth that are not the focus of this paper but will be reported in other publications relating to the outcomes from the DFO study.

\subsection{Procedure}

Following referral to the study, participant details were collected via a screening interview to determine eligibility to proceed to the next stage of assessment and intervention. Pre-intervention measures were mailed out to eligible participants for completion. No blinding procedures for those collecting the data were employed. Parents and youth signed informed consent forms, with the understanding of random assignment to treatment as part of a within-subjects controlled trial investigating the treatment of anxiety, depression and substance misuse in youth. Ineligible participants were referred to appropriate local agencies. Assessment measures were repeated at post-intervention and at six month follow-up.

The interventions were delivered by supervised Clinical Psychology trainees who were undertaking Masters or Doctoral level training at Deakin University, and had completed 2 full days of training in the specific interventions. Treatment manuals for the two interventions specified the session content, and sessions were recorded and periodically reviewed to ensure fidelity to the manual.

The BEST Plus program is a fully manualised and evidence supported treatment $[30,46]$. It consists of a structured eight-week, professionally-led group program designed to assist parents concerned with youth substance-related problems, and aims to increase family cohesion with the use of homework tasks. Parents are encouraged to attend all eight sessions, with youth of concern and siblings invited to also attend the final four weeks of the program. In addition to providing a supportive environment, the BEST Plus intervention targeted some of the relevant parent factors suggested to maintain parent and youth anxiety, including parental over-involvement, parental assumptions and beliefs, and family conflicts and dysfunction $[30,46]$. Parents were invited to reflect on their experiences in relation to these factors, and to explore new ways of thinking about their situation via group discussion and metaphors. Increased family cohesion was targeted through weekly family homework tasks, and a whole-of-family approach. Psycho-education was provided relating to adolescent development, including need for individuation and increasing youth responsibility. Parents also participated in communication skills training and were encouraged to be assertive in setting and negotiating effective boundaries and consequences with their young person. Two themes returned to throughout the program were the importance of parent 
self-care and the need to begin by making small changes to improve family functioning.

The Cognitive Behavioural Therapy (CBT) intervention for youth, known as Self-Help for Alcohol/other drug use and Depression for Young people or "SHADEY" was developed by Steven Carroll, Leanne Hides and colleagues at ORYGEN Youth Health in Melbourne [62, 63]. This program was designed for youth presenting with depression and substance-use related issues. It consists of a 10 week one-to-one youth CBT manualised program based on symptoms-focused session content, use of structured homework tasks and the use of Aaron Beck's model for addressing unhelpful cognitions such as negative self-appraisals. It utilizes elements of psycho-education, motivational interviewing, mood monitoring, coping skills training, cognitive reframing, mindfulness and relapse prevention. Young people who participated in this treatment were seen on a weekly basis across 10 weeks.

Participants assigned to the combined treatment condition (i.e. CBT supplemented with BEST Plus) participated in both treatments run partially in parallel over 12 14 weeks.

\section{RESULTS}

\subsection{Sample Characteristics}

Demographics of the sample were analyzed by group as previously described, and are presented in Table 1. Regarding the clinical characteristics of the sample, at baseline (T1) $52.2 \%$ of those who completed pre measures were above the sub-clinical cut off point for anxiety on the Millon Clinical Multiaxial Inventory (MCMI-III), and $29.9 \%$ of those who went on to also complete post measures were in the (sub)clinical range or higher at baseline. For MCMI-III avoidance, $47.8 \%$ were subthreshold or higher at T1, and $35.4 \%$ of those who completed post measures were above this threshold at entry to the study. Finally for MCMI-III compulsive traits, $47.8 \%$ of parents who entered the study initially were above the sub-clinical cut off for compulsive traits, where as $68.7 \%$ of those who completed both pre and post measures reported compulsive traits at sub-threshold or higher at baseline. Further details are presented in Table 2.

Chi square tests and independent samples t-tests were run according to group, and did not reveal any significant differences between the BEST Plus and NONBEST Plus groups within any of the reported categories for parent or youth age or gender, or parent baseline anxiety characteristics (see Tables 1 and 2).

\subsection{Outcome Data}

Changes in mean scores and standard deviations from pre- to post-assessment are presented in Table 3, for the anxiety and attachment variables. In order to test the study hypotheses, repeated measures general linear modeling was used to evaluate changes in parent anxiety and attachment from pre- to post-assessment across the BEST Plus and NONBEST Plus groups.

Repeated measures outcomes for anxiety, avoidant, and compulsive subscales of the MCMI-III, and the anxious and avoidant attachment subscales of the RSQ, are also presented in Table 3.

\subsection{MCMI-III Anxiety Outcomes}

As expected, MCMI-III parent anxiety reduced following the BEST Plus intervention (mean difference was 11.5 from pre to post-assessment, $\mathrm{F}(1.38)=4.3, \mathrm{p}<0.05)$. Incontrast, MCMI-III anxiety in the NONBEST Plus group tended to increase from pre to post- assessment (mean difference of 13.4, p < 0.05). This interaction effect between pre-post changes in anxiety and treatment condition was significant $(\mathrm{F}(1.46)=5.9, \mathrm{p}<0.05)$ (see Table 3). Reductions during post assessment on MCMIIII avoidant traits compared with pre-assessment, while non-significant increases were evident in the NONBEST Plus group. These reductions were greater for the BEST Plus group $(\mathrm{F}(1.38)=4, \mathrm{p}>0.05)$ than for the NONBEST Plus group $(\mathrm{F}(1.8)=0.9)$ (mean differences were

Table 2. Baseline clinical characteristics of the sample.

\begin{tabular}{|c|c|c|c|c|c|}
\hline & $\begin{array}{l}\text { Measures } \\
\text { completed }\end{array}$ & $\begin{array}{c}\text { Total above } \\
\text { sub-clinical cutoff }(n)\end{array}$ & $\begin{array}{c}\text { BEST Plus above } \\
\text { sub-clinical cutoff }(n)\end{array}$ & $\begin{array}{l}\text { NONBEST Plus above } \\
\text { sub-clinical cutoff }(n)\end{array}$ & $\begin{array}{l}\text { Between-groups } \\
\text { difference }\left(\chi^{2}\right)\end{array}$ \\
\hline \multirow[t]{2}{*}{ Parent MCMI Anxiety } & Pre only & $12(52.2 \%)$ & $8(47.1 \%)$ & $4(66.7 \%)$ & \\
\hline & Pre-post & $14(29.2 \%)$ & $13(33.3 \%)$ & $1(11.2 \%)$ & $\chi^{2}(1)=2.85, p=0.09$ \\
\hline \multirow[t]{2}{*}{ Parent MCMI Avoidant } & Pre only & $11(47.8 \%)$ & $8(47.1 \%)$ & $3(50 \%)$ & \\
\hline & Pre-post & $17(35.4 \%)$ & $14(35.9 \%)$ & $3(33.3 \%)$ & $\chi^{2}(1)=0.37, p=0.54$ \\
\hline \multirow[t]{2}{*}{ Parent MCMI Compulsive } & Pre only & $11(47.8 \%)$ & $7(41.2 \%)$ & $4(66.7 \%)$ & \\
\hline & Pre-post & $33(68.7 \%)$ & $26(66.7 \%)$ & $7(77.8 \%)$ & $\chi^{2}(1)=1.0, p=0.32$ \\
\hline
\end{tabular}


Table 3. Parent anxiety and attachment following BEST Plus and NONBEST Plus $(n=48)$.

\begin{tabular}{|c|c|c|c|c|}
\hline \multirow{2}{*}{ MCMI-III Subscale } & \multirow[t]{2}{*}{$n$} & \multirow{2}{*}{$\frac{\text { Pre }}{\mathrm{M}(\mathrm{SD})}$} & \multicolumn{2}{|r|}{ Post } \\
\hline & & & $\mathrm{M}(\mathrm{SD})$ & $\mathrm{F}$ \\
\hline \multicolumn{5}{|l|}{ Anxiety } \\
\hline BEST Plus & 39 & 38.7 (32.9) & $27.2(27.9)$ & $\mathrm{F}(1.38)=4.3^{* *}$ \\
\hline NONBEST & 9 & $24.5(27.6)$ & $37.9(35.1)$ & $F(1.8)=2.8$ \\
\hline Treatment $\times$ Time & & & & $\mathrm{F}(1.46)=5.9^{* *}$ \\
\hline \multicolumn{5}{|l|}{ Avoidant } \\
\hline BEST Plus & 39 & $42(27.1)$ & $35.6(27.5)$ & $\mathrm{F}(1.38)=4^{* *}$ \\
\hline NONBEST & 9 & $35.5(27.5)$ & $39.2(28.2)$ & $\mathrm{F}(1.8)=0.9$ \\
\hline Treatment $\times$ Time & & & & $\mathrm{F}(1.46)=1.9$ \\
\hline \multicolumn{5}{|l|}{ Compulsive } \\
\hline BEST Plus & 39 & $63.6^{\dagger}(17.3)$ & $67^{\dagger}(17.5)$ & $\mathrm{F}(1.38)=1.2$ \\
\hline NONBEST & 9 & $73.1^{\lambda}(16.7)$ & $73.1^{\lambda}(10.7)$ & $\mathrm{F}(1.8)=0$ \\
\hline Treatment $\times$ Time & & & & $F(1.46)=0.26$ \\
\hline \multicolumn{5}{|l|}{$\begin{array}{c}\text { Attachment } \\
\text { Relationship Styles }\end{array}$} \\
\hline \multicolumn{5}{|l|}{ Avoidant Attachment } \\
\hline BEST Plus & 38 & $21.6(3.6)$ & $21.7(3.6)$ & $\mathrm{F}(1.37)=0.2$ \\
\hline NONBEST & 9 & $20.8(4.1)$ & $23.2(2.2)$ & $\mathrm{F}(1.8)=3.6^{*}$ \\
\hline Treatment $\times$ Time & & & & $\mathrm{F}(1.45)=3.6^{*}$ \\
\hline \multicolumn{5}{|l|}{ Anxious Attachment } \\
\hline BEST Plus & 39 & $10.8(4.8)$ & $9.9(4.3)$ & $\mathrm{F}(1.38)=1.1$ \\
\hline NONBEST & 9 & $11.7(5.5)$ & $12.2(5.2)$ & $F(1.8)=1.4$ \\
\hline Treatment $\times$ Time & & & & $F(1.46)=1.6$ \\
\hline
\end{tabular}

" significant at the $\mathrm{p}<0.05$ level ( 1 tailed); ${ }^{* *}$ significant at the $\mathrm{p}<0.05$ level ( 2 tailed); ${ }^{\dagger}$ above the sub-clinical cut off for MCMI-III pathology; ${ }^{\lambda}$ above the clinical cut off for MCMI-III pathology.

7.5 and 5.5 respectively).

Unexpectedly, there was no significant change between pre and post assessment on MCMI-III compulsive traits. In the NONBEST Plus group, the mean MCMI-III compulsive traits score remained within the clinical range from $\mathrm{T} 1$ assessment to at $\mathrm{T} 2$, whereas for the BEST Plus group, the mean compulsive traits score remained within the sub-clinical range from pre- to postassessment with a slight but non-significant increase following treatment.

\subsection{Anxiety Outcomes at Six Month Follow-Up}

Further general linear modeling was run to analyze all three time points including 6-month follow-up, for the limited data available on MCMI-III subscales (see Table 4). There was a statistically significant difference between the two treatments for parent's levels of anxious distress, as measured by MCMI-III anxiety $(\mathrm{F}(2.23)=3.3)$ and avoidant $(\mathrm{F}(2.23)=2.7)$ subscales. The effect of BEST Plus on parent anxiety had decreased at T3,
Table 4. Parent anxiety six-months following BEST Plus and NONBEST Plus $(n=24)$.

\begin{tabular}{cccccc}
\hline & $n$ & Pre & Post & \multicolumn{2}{c}{ Follow-Up } \\
\hline $\begin{array}{c}\text { MCMI-III } \\
\text { Subscale }\end{array}$ & M (SD) & M (SD) & M (SD) & F \\
Anxiety & & & & & \\
BEST Plus & 24 & $42(30.1)$ & $28.9(27.4)$ & $36.5(26.3)$ & $\mathrm{F}(2.22)=6^{* *}$ \\
NONBEST & 2 & $3(4.2)$ & $30.5(41.7)$ & $36(33.9)$ & N/A \\
$\begin{array}{c}\text { Treatment } \\
\times \text { Time }\end{array}$ & & & & $\mathrm{F}(2.23)=3.3^{*}$ \\
Avoidant & & & & & \\
$\begin{array}{c}\text { BEST Plus } \\
24\end{array}$ & $49(27.4)$ & $42.6(29.9)$ & $44.3(26.8)$ & $\mathrm{F}(2.22)=1.8$ \\
$\begin{array}{c}\text { NONBEST } \\
\text { Treatment }\end{array}$ & $5.5(7.8)$ & $15(4.2)$ & $38.5(30.5)$ & $\mathrm{N} / \mathrm{A}$ \\
$\times$ Time & & & & $\mathrm{F}(2.23)=2.7^{*}$ \\
Compulsive & & & & & \\
BEST Plus & 24 & $64.1^{\dagger}(19.4)$ & $66.8^{\dagger}(19.1) 60.2^{\dagger}(21.1)$ & $\mathrm{F}(2.22)=1.1$ \\
$\begin{array}{c}\text { NONBEST } \\
\text { Treatment } \\
\times \text { Time }\end{array}$ & $62.5^{\dagger}(16.3)$ & $68^{\dagger}(14.1)$ & $69^{\dagger}(15.6)$ & N/A \\
\hline
\end{tabular}

" significant at the $\mathrm{p}<0.05$ level ( 1 tailed); ${ }^{* *}$ significant at the $\mathrm{p}<0.01$ level (1 tailed); ' ${ }^{\dagger}$ above the sub-clinical cut off for MCMI-III pathology.

butremained improved overall compared with the mean scores for this group at $\mathrm{T} 1(\mathrm{~F}(2.22)=6, \mathrm{p}<0.01)$.

At T3 (6-months follow-up), both groups were demonstrating similar rates of MCMI-III anxiety, however this was an improvement for the BEST Plus group and a marked deterioration for the small number of NONBEST Plus parents completing follow-up. Given the small numbers in the NONBEST Plus group at follow-up, however, multivariate testing could not be reliably run with this group (see Table 4). Avoidance on the MCMIIII showed a decreasing trend from $\mathrm{T} 1$ to $\mathrm{T} 2$, and then increased again slightly to T3 for the BEST Plus group.

In contrast, avoidance on the MCMI-III increased steadily over time for the NONBEST Plus group, and the difference between these two patterns was statistically significant $(\mathrm{F}(2.23)=2.7)$. Despite a non-significant decrease in compulsive traits at 6 month follow-up for BEST compared assessment and with NONBEST, no significant difference between groups was found for the compulsive scale at the 6 month follow-up evaluations.

\subsection{Intention to Treat}

The pre-post general linear analyses were re-run as intention to treat analyses using the original 3 groups (CBT, COMBINED and BEST Plus). A similar pattern of find ings was observed, such that the groups randomized to BEST Plus and COMBINED generally fared somewhat better than the group randomized to $\mathrm{CBT}$ on anxiety $(\mathrm{F}(2.45)=1.2, \mathrm{p}>0.05)$ and avoidant traits $(\mathrm{F}(2.45)=$ $0.77, \mathrm{p}>0.05)$ and avoidant attachment $(\mathrm{F}(2.44)=1.9, \mathrm{p}$ 
$>0.05$ ) over time. However these results were limited by small numbers in each cell given the three groups, and demonstrated non-significant effects; as did anxious attachment $(\mathrm{F}(2.45)=0.58, \mathrm{p}>0.05)$ and compulsive traits $(\mathrm{F}(2.45)=0.89, \mathrm{p}>0.05)$.

\section{DISCUSSION}

The Deakin Family Options (DFO) pilot study compared the relative efficacy of a family-based treatment involveing parents (BEST Plus), an individually based treatment for youth (CBT), and a combined condition, for families of youth presenting with high prevalence youth mental health problems. The broad aim of the DFO Pilot Study was to determine whether families receiving the BEST Plus would experience greater reductions in youth and parent mental health symptoms, and improved parentchild relationships, compared with those in the CBT condition. The aim of this paper is to describe changes in parent anxiety and attachment, dependent upon whether the parent did or did not participate in a treatment group with other parents. It was hypothesized that parents in the BEST Plus condition would experience greater reductions in levels of anxiety on the three MCMI-III anxiety related subscales, and also greater reductions in self-reported anxious and avoidant attachment, compared with parents in the NONBEST Plus condition. These hypotheses were partially supported.

Parent anxiety was measured at T1 (entry to the study), T2 (post-intervention, or after 12 weeks for the no treatment group), and T3 (6-month follow up) on three different clinical subscales of the MCMI-III (anxiety, avoidant and compulsive). In our sample, parents initially presented with high rates of compulsive trait anxiety above a sub-threshold clinical cut off on the MCMIIII compared with normative samples [51]. MCMI-III anxiety and avoidance were initially higher in the BEST Plus group than the NONBEST Plus group, but this pattern reversed following treatment and at 6-month follow up for anxiety, suggesting a significant impact of parent participation in a treatment group on anxiety. Regarding MCMI-III avoidant traits, the BEST Plus significantly reduced from pre to post assessment on this trait, while the NONBEST Plus group did not change- - however this difference between groups was not significant. For the small sample of participants who returned follow up data, however, there was a significant difference between BEST Plus and NONBEST Plus groups. Whilst the BEST Plus group maintained a slightly decreased but relatively stable pattern of MCMI-III avoidant personality patterns from pre to post and follow up, those in the NONBEST Plus group increased steadily over time on this trait. This finding must be interpreted with caution given the very small number of parents who returned all three assessments in the NONBEST Plus group.
Given that anxiety is a "clinical syndrome" subscale on the MCMI-III, representing a construct pertaining to "Axis I" pathology in the DSM-IV [2], it is perhaps reasonable to expect that this measure would be more sensitive to significant changes in a shorter period of time (e.g. 12 weeks) compared with subscales pertaining to DSMIV "Axis II" syndromes. The MCMI-III "personality pattern" subscales, including the compulsive and avoidant subscales, were designed to measure DSM "Axis II" pathology. By definition, the Axis II disorders relate to more enduring and stable features present in an individual than the Axis I disorders [2,52]. Therefore, whilst the expression of Axis II symptoms may increase or decrease over time, the symptoms should be less sensitive to change in a relatively short period of time compared with MCMI-III Axis I "clinical syndromes". This, combined with a relatively small sample, perhaps accounts for the non-significant findings relating to MCMI-III compulsive and avoidant traits between pre and post assessment.

This study included a sample with higher compulsive traits than the general population (mean presenting scores fell within the sub-clinical range for BEST Plus and the clinical range for NONBEST Plus groups). The compulsive scale reflects an individual's adaptive style. Individuals with this particular style may be described as perfectionist and meticulous; high achievers who perform well with schedules, deadlines and rules to provide them with an increased sense of control. They function well generally, often presenting to therapy with anxiety-related difficulties only when faced with excessive change [64]. The current study may have inadvertently attracted individuals with this type of adaptive style. Parents with a compulsive style may have sought out assistance to help them improve their perceived sense of control over what may have been becoming an increasingly chaotic home environment - with the emergence of their adolescent's mental health difficulties and associated problem behaviours. The BEST Plus intervention comprised a structured eight week program which provided parents with tools (such as homework tasks) to improve family cohesion. This treatment may have maintained parent's control tendencies somewhat, with a focus on increasing parental control and empowerment within the family system [30]. Thus parents in the BEST Plus group continued to experience compulsive symptoms on the MCMI-III in the "sub-clinical range" on average at post-assessment. In comparison, parents in the NONBEST Plus were not exposed to these concepts. However, in the absence of any specific support or intervention, these parent's compulsive traits remained within the clinical range at post-assessment.

Overall this evaluation was perhaps better able to observe changes in MCMI-III anxiety "clinical syndrome" symptoms, as parents demonstrating these symptoms 
may have been more likely to enter the study and decrease these anxiety symptoms via treatment. Parents in the BEST Plus treatment discussed their difficulties with other parents experiencing similar issues, and in doing so, normalized their experiences. Qualitative information obtained from a consumer reference group held at the end of the project [13] suggested that the BEST Plus program had achieved this goal of offering a supportive environment, likely to alleviate parental anxiety symptoms. For example, participants reported enjoying the collegial atmosphere of the BEST Plus group, contributing their experiences to help others in the group, and receiving advice, understanding and support from other members. Parents also described feeling less isolated through the sharing of experiences, which also helped to normalize the behaviour of their young person and reduce levels of self-blame and guilt [13]. A supportive therapeutic relationship such as this has been shown to be a key component of change across numerous psychotherapies, including psychoanalytic [65] and cognitive-behavioural approaches [66], amongst others [67].

It is interesting that the change in the avoidance subscale on the MCMI-III was not significantly different across groups between pre and post assessment, while the avoidance subscale of the RSQ was (and this pattern was approaching 2-tailed significance). There are differences between attachment avoidance and the MCMI-III "avoidant personality pattern" that may help to explain this finding. Attachment avoidance assesses parent's level of avoidant coping in significant close relationships (e.g. with their partner and children), whereas the MCMI-III "avoidant personality pattern" pertains to the individual's use of an avoidant response in a range of situations where the person feels timid, generalized social anxiety, and the need for social avoidance [68]. As the parents entering the DFO pilot study knew that they may be assigned to attend a group-based treatment with other families, it is unlikely that they would have commenced the assessment process if they had significant avoidant personality traits, and thus there would have been less room for change on this variable. Indeed, the mean score on this MCMI-III subscale for parents entering the study in both groups was well below the subclinical cut-off. The increase in attachment anxiety was small but significant for NONBEST Plus compared with BEST Plus from pre to post assessment. It may be that most parents facing the difficult prospect of caring for youth with mental health problems become increasingly avoidant in their attachment style across time as a means of coping with the day to day challenges, and yet involvement in a family based treatment helps to curtail this natural (and yet potentially unhelpful) coping tendency. This possibility is supported by the increased difference between the BEST Plus and NONBEST Plus groups at six month follow-up, but requires further testing with larger samples and additional follow up points.

Following the BEST Plus intervention compared with the no treatment control group there were also small non-significant improvements in compulsive traits at follow-up and anxious attachment at post-assessment, and post-assessment maintenance (rather than a decrease) in avoidant attachment. These findings suggest that it may be prudent to trial a modification of the BEST Plus intervention for families where the youth presents with a high prevalence mental health problem. Previous applications of this program have primarily targeted youth with substance using (externalising) presentations, and demonstrated changes in parent mental health compared with a wait list control group [29]. The DFO sample also recruited families of youth with internalising problems as their primary presenting concern, and the impact on parents were perhaps less strong (as described above). Some of the concepts of primary focus in BEST Plus are parental self-care, limit setting and "letting go"-handing more responsibility and consequences for their actions to youth. It is possible that these BEST Plus program concepts that emphasise "firmness" within the parenting style may be the effective components with externalising and substance use problems, without requiring as much focus on the "warmth" in the authoritative parenting style. It is possible that more balanced emphasis on both warmth and firmness may be required in relation to youth with internalising presentations. Commonly, these presenting issues co-occur.

Given this, a new randomized controlled trial has commenced (ACTRN\#12612000398808), designed to evaluate a new version of the BEST Plus intervention (BEST MOOD) [69] for parent and youth mental health; including parent anxiety. The changes to the BEST program in BEST MOOD place greater emphasis on parent-child attachment, connection, encouragement and instilling hope for change in the youth in the family system; in an attempt to balance the focus on parental control and boundary setting aimed at changing maladaptive child behaviours. The BEST MOOD manual does however attempt to retain the components of the therapy relating to psycho-education, metaphor, clear communication, and negotiation of limits with increasingly individuating adolescents. It remains to be seen whether these modifications may have a greater impact on parent anxiety as well as other aspects of parent and youth mental health.

In interpreting the results of this DFO trial, limitations of the study are noted. A general difficulty with the current study was small comparative group sizes, particularly in the 6-month follow up group; which occurred despite initial screening of a large number of families. High attrition rates and incomplete outcome measures 
were contributing factors. Difficulty engaging youth in the study and hence treatment also resulted in a particularly small sample for the CBT group, consistent with previously reported low rates of uptake for youth mental health services [43]. Therefore, interventions in this area may do well to focus attention on specific methods of engaging and retaining youth in treatment.

In summary, this whole-of-family targeted approach was aimed at improving parent and youth mental health and parenting competence, and also at providing assistance to youth and siblings where they could be engaged. Overall these findings provide initial, albeit limited, support for this type of family based intervention as a potentially efficacious model for improving parent anxiety and attachment in parents of youth with high prevalence mental health conditions. Qualitative information gathered from parents in a post intervention focus group supported the preliminary quantitative findings of this study [13], relating to decreased parent stress and increased perceived coping in parents. Given the literature relating to high rates of stress and burnout in parents and carers, this study provides an important initial contribution as a potentially beneficial treatment for anxious parents of depressed, anxious and substance misusing youth.

\section{ACKNOWLEDGEMENTS}

This paper uses data from Deakin Family Options (DFO) study which was funded by beyondblue: the national depression initiative and the Centre for Mental Health and Well Being Research, Deakin University. The DFO study was a partnership between Deakin University and drummond street services. The authors would like to thank Reima Pryor, Jaclyn Danaher, Louise McDonald, Ian Shephard, Daniel Condon, Sophie McIntosh, Catherine Bull, Jenni Shannahan, Olivia Morrow and Helen Rimington for their assistance with assessments, data collection, group facilitation, training and supervision.

\section{REFERENCES}

[1] Freeman, A. and DiTomasso, R.A. (1957) Cognitive concepts of anxiety. In: Stein, D.J. and Hollander, E., Eds., Textbook of Anxiety Disorders. American Psychiatric Publishing Inc., Washington DC, 37-60.

[2] American Psychiatric Association (2000) Diagnostic and statistical manual of mental disorders. American Psychiatric Association Inc., Washington DC.

[3] Australian Bureau of Statistics (2007) National survey of mental health and wellbeing: Summary of results. Australian Bureau of Statistics, Canberra.

[4] Cummings, E.M., Davies, P.T. and Campbell, S.B. (2002) Developmental psychopathology and family process: Theory, research, and clinical implications. Guilford Press, New York.

[5] Champagne, F. and Meaney, M.J. (2001) Like mother, like daughter: Evidence for non-genomic transmission of parental behavior and stress responsivity. Progress in Brain Research, 133, 287-302. doi:10.1016/S0079-6123(01)33022-4

[6] Nolte, T., Guiney, J., Fonagy, P., Mayes, L.C. and Luyten, P. (2011) Interpersonal stress regulation and the development of anxiety disorders: An attachment-based developmental framework. Frontiers in Behavioral Neuroscience, 5, 55. doi:10.3389/fnbeh.2011.00055

[7] Hudson, J.L. and Rapee, R.M. (2011) Parent-child interactions and anxiety disorders: An observational study. Behaviour Research and Therapy, 39, 1411-1427. doi:10.1016/S0005-7967(00)00107-8

[8] Cole, D.A., Peeke, L.G. and Martin, J.M. (1998) A longitudinal look at the relation between depression and anxiety in children and adolescents. Journal of Consulting and Clinical Psychology, 66, 451-459. doi:10.1037/0022-006X.66.3.451

[9] Bogels, S.M. and Brechman-Toussaint, M.L. (2006) Family issues in child anxiety: Attachment, family functioning, parental rearing and beliefs. Clinical Psychology Review, 26, 834-856. doi:10.1016/j.cpr.2005.08.001

[10] Wood, J.J., Piacentini, J.C. and Southam-Gerow M. (2006) Family cognitive behavioural therapy for child anxiety disorders. American Academy of Child and Adolescent Psychiatry, 45, 314-321. doi:10.1097/01.chi.0000196425.88341.b0

[11] Raina, P., O’Donnell, M., Schwellnus, H., Rosenbaum, P., King, G. and Brehaut, J. (2004) Caregiving process and caregiver burden: Conceptual models to guide research and practice. Pediatrics, 115, 626-636. doi:10.1542/peds.2004-1689

[12] Angold, A., Messer, S.C., Stangl, D., Farmer, E.M. and Costello, E.J. (1998) Perceived parental burden and service use for child and adolescent psychiatric disorders. American Journal of Public Health, 88, 75-80. doi:10.2105/AJPH.88.1.75

[13] Lewis, A.J., Bertino, M.D., Robertson, N., Knight, T. and Toumbourou, J. (2012) Consumer feedback following participation in a family-based intervention for youth mental health. Depression Research and Treatment, 2012, 8. doi: $10.1155 / 2012 / 235646$

[14] Cuijpers, P., Geraedts, A.S. and van Oppen, P. (2011) Interpersonal psychotherapy for depression: A meta-analysis. American Journal of Psychiatry, 168, 581-592. doi:10.1176/appi.ajp.2010.10101411

[15] Silverman, W.K., Kurtines, W.M., Jaccard, J. and Pina, A.A. (2009) Directionality of change in youth anxiety treatment involving parents: An initial examination. Journal of Consulting and Clinical Psychology, 3, 474-485. doi: $10.1037 / \mathrm{a} 0015761$

[16] Weisz, J.R., McCarty, C.A. and Valeri S.M. (2006) Effects of psychotherapy for depression in children and adolescents: A meta-analysis. Psychological Bulletin, 132, 132-149. doi:10.1037/0033-2909.132.1.132

[17] Albano, A.M. and Kendall, P.C. (2002) Cognitive behavioural therapy for children and adolescents with anxiety disorders: Clinical research advances. International Review of Psychiatry, 14, 129-134. 


\section{doi:10.1080/09540260220132644}

[18] Baer, J.S., Beadnell, B., Garrett, S.B., Hartzler, B., Wells, E.A. and Peterson, P.L. (2008) Adolescent change language within a brief motivational intervention and substance use outcomes. Psychology of Addictive Behaviors, 22, 570-575. doi:10.1037/a0013022

[19] Tevyaw, T.O. and Monti, P.M. (2004) Motivational enhancement and other brief interventions for adolescent substance abuse: Foundations, applications and evaluations. Addiction, 99, 63-75. doi:10.1111/j.1360-0443.2004.00855.x

[20] Kaminer, Y., Burleson, J.A. and Goldberger, R. (2002) Cognitive-behavioral coping skills and psychoeducation therapies for adolescent substance abuse. The Journal of Nervous and Mental Disease, 190, 737-745. doi:10.1097/00005053-200211000-00003

[21] Flannery-Schroeder, E.C. and Kendall, P.C. (2000) Group and individual cognitive-behavioral treatments for youth with anxiety disorders: A randomized clinical trial. Cognitive Therapy and Research, 24, 251-278. doi:10.1023/A:1005500219286

[22] Clarke, G., Hops, H., Lewinsohn, P.M., Andrews, J.A., Seeley, J.R. and Williams, J.A. (1992) Cognitive-behavioral group treatment of adolescent depression: Prediction of outcome. Behavior Therapy, 23, 341-354. doi:10.1016/S0005-7894(05)80162-5

[23] Silverman, W.K., Kurtines, W.M., Ginsburg, G.S., Weems, C.F., Lumpkin, P.W. and Carmichael, D.H. (1999) Treating anxiety disorders in children with group cognitivebehavioral therapy: A randomized clinical trial. Journal of Consulting and Clinical Psychology, 67, 995-1003. doi:10.1037/0022-006X.67.6.995

[24] Barrett, P.M., Dadds, M.R. and Rapee R.M. (1996) Family treatment of childhood anxiety: A controlled trial. Journal of Consulting and Clinical Psychology, 64, 333-342. doi:10.1037/0022-006X.64.2.333

[25] Kendall, P.C., Flannery-Schroeder, E., Panichelli-Mindel, S.M., Howard, M. and Siqueland, B. (1997) Therapy for youths with anxiety disorders: A second randomized clinical trial. Journal of Consulting and Clinical Psychology, 65, 366-380. doi:10.1037/0022-006X.65.3.366

[26] Kendall, P.C., Hudson, J.L., Gosch E., Flannery-Schroeder, E. and Suveg, C. (2008) Cognitive-behavioral therapy for anxiety disordered youth: A randomized clinical trial evaluating child and family modalities. Journal of Consulting and Clinical Psychology, 76, 282-297. doi:10.1037/0022-006X.76.2.282

[27] Brent, D.A., Holder, D., Kolko, D., Birmaher, B., Baugher, M., Roth, C., Iyengar, S. and Johnson, B.A. (1997) A clinical psychotherapy trial for adolescent depression comparing cognitive, family, and supportive therapy. Archives of General Psychiatry, 54, 855-877. doi:10.1001/archpsyc.1997.01830210125017

[28] Liddle, H.A., Dakof, G.A., Parker, K., Diamond, G.S., Barrett, K. and Tejeda, M. (2001) Multidimensional family therapy for adolescent drug abuse: Results of a randomized clinical trial. The American Journal of Drug and Alcohol Abuse, 27, 651-688. doi:10.1081/ADA-100107661
[29] Toumbourou, J.W., Blyth, A., Bamberg, J. and Forer, D. (2001) Early impact of the BEST intervention for parents stressed by adolescent substance abuse. Journal of Community \& Applied Social Psychology, 11, 291-304. doi: $10.1002 /$ casp. 632

[30] Bamberg, J., Findley, S. and Toumbourou J. (2006) The best plus approach to assisting families recover from youth substance problems. Youth Studies Australia, 25, 25-32.

[31] Cobham, V.E., Dadds, M.R., Spence, S.H. and McDermott, B. (2010) Parental anxiety in the treatment of childhood anxiety: A different story three years later. Journal of Clinical Child \& Adolescent Psychology, 39, 410-420. doi:10.1080/15374411003691719

[32] Wood, J.J., Piacentini, J.C., Southam-Gerow, M., Chu, B. and Sigman, M. (2006) Family cognitive behavioral therapy for child anxiety disorders. Journal of the American Academy of Child \& Adolescent Psychiatry, 45, 314-321. doi:10.1097/01.chi.0000196425.88341.b0

[33] Liber, J.M., van Widenfelt, B.M. Goedhart, A.W., Utens, E.M. and van der Leeden, M. (2008) Parenting and parental anxiety and depression as predictors of treatment outcome for childhood anxiety disorders: Has the role of fathers been underestimated? Journal of Clinical Child \& Adolescent Psychology, 37, 747-758. doi:10.1080/15374410802359692

[34] Khanna, M.S. and Kendall, P.C. (2009) Exploring the role of parent training in the treatment of childhood anxiety. Journal of Consulting and Clinical Psychology, 77, 981-986. doi:10.1037/a0016920

[35] Victor, A.M., Bernat, D.H., Bernstein, G.A. and Layne, A.E. (2007) Effects of parent and family characteristics on treatment outcome of anxious children. Journal of Anxiety Disorders, 21, 835-848. doi:10.1016/j.janxdis.2006.11.005

[36] Crawford, A.M. and Manassis, K. (2001) Familial predictors of treatment outcome in childhood anxiety disorders. Journal of the American Academy of Child \& Adolescent Psychiatry, 40, 1182-1189. doi:10.1097/00004583-200110000-00012

[37] Podell, J.L. and Kendall, P.C. (2011) Mothers and fathers in family cognitive-behavioral therapy for anxious youth. Journal of Child and Family Studies, 20, 182-195. doi:10.1007/s10826-010-9420-5

[38] Southam-Gerow, M.A., Kendall, P.C. and Weersing, V.R. (2001) Examining outcome variability: Correlates of treatment response in a child and adolescent anxiety clinic. Journal of Clinical Child Psychology, 30, 422-436. doi:10.1207/S15374424JCCP3003 13

[39] Restifo, K. and Bögels, S. (2009) Family processes in the development of youth depression: translating the evidence to treatment. Clinical Psychology Review, 29, 294-316. doi:10.1016/j.cpr.2009.02.005

[40] David-Ferdon, C. and Kaslow, N.J. (2008) Evidencebased psychosocial treatments for child and adolescent depression. Journal of Clinical Child \& Adolescent Psychology, 37, 62-104. doi:10.1080/15374410701817865

[41] Harrison, M.E., McKay, M.M. and Bannon, W.M. (2004) Inner-city child mental health service use: The real ques- 
tion is why youth and families do not use services. Community Mental Health Journal, 40, 119-131. doi:10.1023/B:COMH.0000022732.80714.8b

[42] French, R., Reardon, M. and Smith P. (2003) Engaging with a mental health service: Perspectives of at-risk youth. Child and Adolescent Social Work Journal, 20, 529-548. doi:10.1023/B:CASW.0000003142.13457.0a

[43] Sawyer, M.G., Arney, F.M. and Baghurst, P. (2000) The mental health of young people in Australia. Mental Health and Special Programs Branch, Commonwealth Department of Health and Aged Care, Canberra.

[44] Shaffer, D., Gould, M.S., Fisher, P., Moreau, D., Kleinman, M. and Flory, M. (1996) Psychiatric diagnosis in child and adolescent suicide. Archives of General Psychiatry, 53, 339-348. doi:10.1001/archpsyc.1996.01830040075012

[45] Morrissey-Kane, E. and Prinz, R.J. (1999) Engagement in child and adolescent treatment: The role of parental cognitions and attributions. Clinical Child and Family Psychology, 2, 183-198. doi:10.1023/A:1021807106455

[46] Toumbourou, J.W. and Bamberg, J.H. (2008) Family recovery from youth substance use related problems: A pilot study of the BEST plus program. Substance Use \& Misuse, 43, 1829-1843. doi:10.1080/10826080802297385

[47] Bertino, M.D., Lewis, A., Toumbourou, J., Ricciardelli, L. and Knight, T. (2010) Family therapy and cognitive-behavioral therapy for youth with depression, anxiety and substance disorders. Proceedings of the 27th International Congress of Applied Psychology, 11-16 July 2010, Melbourne, 232-233.

[48] Achenbach, T.M. (1991) Manual for the youth self-report and 1991 profile. Department of Psychiatry, University of Vermont, Burlington.

[49] Achenbach, T.M. (1997) Manual for the young adult self-report and young adult behaviour checklist. Department of Psychiatry, University of Vermont, Burlington.

[50] Miller, G.A. and Lazowski, L.E. (2001) Adolescent SASSIA2 manual. SASSI Institute, Springville.

[51] Millon, T., Davis, R.D. and Millon, C. (1997) MCMI-III manual. National Computer Systems, Minneapolis.

[52] American Psychiatric Association (1980) Diagnostic and statistical manual of mental disorders. American Psychiatric Association, Washington DC.

[53] Groth-Marnet, G. (2009) Handbook of psychological assessment. John Wiley \& Sons, Inc., Hoboken.

[54] Blais, M.A., Holdwick, D.J., McLean, R.Y., Otto, M.W., Pollack, M.H. and Hilsenrot, M.J. (2003) Exploring the psychometric properties and construct validity of the MCMI-III anxiety and avoidant personality scales. Journal of Personality Assessment, 81, 237-241. doi:10.1207/S15327752JPA8103 06

[55] Saulsman, L.M. (2011) Depression, anxiety, and the MCMI-III: Construct validity and diagnostic efficiency. Journal of Personality Assessment, 93, 76-83. doi:10.1080/00223891.2010.528481

[56] Griffin, D.W. and Bartholomew, K. (1994) The meta- physics of measurement: The case of adult attachment. In: Bartholomew, K. and Perlman, D., Eds., Attachment Processes in Adulthood, Advances in Personal Relationships. Jessica Kingsley Publishers, London, 17-52.

[57] Hazan, C. and Shaver, P. (1987) Romantic love concepttualized as an attachment process. Journal of Personality and Social Psychology, 52, 511-523. doi:10.1037/0022-3514.52.3.511

[58] Bartholomew, K. and Horowitz, L.M. (1991) Attachment styles among young adults: A test of a four-category model. Journal of Personality and Social Psychology, 61, 226244. doi:10.1037/0022-3514.61.2.226

[59] Collins, N.L. and Read, S.J. (1990) Adult attachment, working models, and relationship quality in dating couples. Journal of Personality and Social Psychology, 58, 644-658. doi:10.1037/0022-3514.58.4.644

[60] Kurdek, L.A. (2002) On being insecure about the assessment of attachment styles. Journal of Social and Personal Relationships, 19, 811-834. doi:10.1177/0265407502196005

[61] Bradford, E. and Lyddon, W.J. (1994) Assessing adolescent and adult attachment: An update. Journal of Counseling \& Development, 73, 215-219. doi:10.1002/j.1556-6676.1994.tb01739.x

[62] Carroll, S., Hides, L., Catania, L., Mathias, S., Greenwood-Smith, C. and Lubman, D.I. (2009) Integrated cognitive behaviour therapy for co-occurring substance misuse and major depression: Lessons from a youth mental health service. Australasian Psychiatry, 17, 365-370. doi:10.1080/10398560902912544

[63] Carroll, S., Kay-Lambkin, F., Baker, A. and Bucci, S. (2009) Self-help for alcohol/other drug use and depresssion for young people-Youth version (SHADE-Y). Orygen Youth Health Research Centre, University of Melbourne and Centre for Mental Health Studies, Parkville, Melbourne.

[64] Groth-Marnat, G. (2009) Millon clinical multiaxial inventory. In: Groth-Marnat, G. and Hoboken, N.J., Eds., Handbook of Psychological Assessment, 5th Edition, John Wiley \& Sons, Inc., New York, 295-334.

[65] Wallerstein, R.S. (1994) Psychotherapy research and its implications for a theory of therapeutic change: A fortyyear overview. The Psychoanalytic Study of the Child, 49, 120-141.

[66] Vocisano, C.K. Klein, D.N. Arnow, B. Dunner, D.L and Gelenberg, P. (2004) Therapist variables that predict symptom change in psychotherapy with chronically depressed outpatients. Psychotherapy: Theory, Research, Practice, and Training, 41, 255-265. doi:10.1037/0033-3204.41.3.255

[67] Harmon, C., Hawkins, E.J., Lambert, M.J., Slade, K. and Whipple, J.L. (2005) Improving outcomes for poorly responding clients: The use of clinical support tools and feedback to clients. Journal of Clinical Psychology, 61, 175-185. doi:10.1002/jclp.20109

[68] Bartholomew, K., Henderson, A. and Dutton, D. (2001) Insecure attachment and abusive intimate relationships. In: Clulow, C., Ed., Adult Attachment and Couple Psycho- 
therapy, Brunner-Routledge, London, 43-61.

[69] Lewis, A., Bertino, M.D., Pryor, R., Toumbourou, J. and Knight, T. Behaviour exchange and systems therapy mood: Treatment manual. Version 1.1, School of Psychology, Deakin University, Melbourne. 